\title{
Uma experiência de ensino do futebol no currículo de \\ licenciatura em Educação Fisica. experiência no 2
}

\author{
Vicente Molina Neto*
}

Resumo

Este trabalho apresenta os resultados de uma investigação de natureza qualitativa realizada em aulas de educação física em escolas públicas da cidade de Porto Alegre-RS. O propósito do estudo foi examinar a relação entre a produção de conhecimento e 3 prática profissional de futuros professores de educação física. A pesquisa enfocou o ensino de um elemento específico da cultura física brasileira (futebol) a estudantes de $5^{\mathrm{a}}$ a $8^{\mathrm{a}}$ série, durante o período de um semestre acadêmico, por 11 estudantes em fase de conclusão de curso, da Escola de Educação Física da Universidade Federal de Rio Grande do Sul. Com referência à organização do currículo, a investigação mostrou a necessidade de rever as condições materiais para as quais as instituições de ensino superior organizam o trabalho pedagógico dos futuros profissionais. Para estes, o trabalho realizado foi uma imersão consciente no ambiente da Escola Pública, especialmente no que diz respeito ao estabelecimento de um programa pedagógico em conformidade com as condições sociais da escola e do grupo. A pesquisa também mostrou que a formação profissional está desconectado das necessidades escolares. Finalmente, a dificuldade dos futuros profissionais para levar a cabo uma pesquisa durante a atividade educacional, mostrou a incongruência entre a produção de conhecimento e as questões fundamentais emergentes da prática da educação física na escola.
Abstract

This work presents the results of a qualitative investigation carried out in physical education classes in the public schools of the city of Porto Alegre -RS. The purpose of the study was to examine the relationship between the production of knowledge in physical education and the professional practice of future physical education teachers. The research focused on the teaching of a specific element of the Brazilian physical culture (soccer) to students of $5^{\text {th }}$ to $8^{\text {th }}$ grades during a period of an academic term by 11 final year undergraduate students of the Faculty of Physical Education of the Federal University of Rio Grande do Sul. With reference to the organization of the curriculum, the investigation showed the need to review the material conditions for which the high education institutions organize the pedagogic work of the future professionals. For the latter, the accomplished work was a councious immersion in the environment of the Public School, especially in respect to the establishment of a teaching programme in accordance with the social conditions of the school and group. The research also showed that the professional training was disconnected from the school needs. Finally, the difficulty of the future professionals to carry out a research during the educational activity showed the incongruity between the production of knowledge and the fundamental questions posed by the practice of physical education teachers in school.

Nesse sentido,
estabeleceu-se
como objetivo
examinar a
relação entre a
produção de
conhecimento e a
prática docente em
educação física
através do ensino
de uma técnica
corporal
específica em
escolas públicas
de Porto Alegre -
RS.

RS. 


\section{INTRODUÇÃO}

Este trabalho é, ao mesmo tempo, o informe de uma investigação realizada em sala de aula e a reconstrução de uma experiência no âmbito do ensino do futebol no currículo de formação dos professores de Educação Física, na ESEF/UFRGS. ${ }^{1} \mathrm{O}$ estudo dá publicidade à reflexão que efetivaram seus participantes sobre os aspectos intrínsecos à técnica corporal, à organização do trabalho pedagógico e à inserção do futebol no entorno social.

Como em outra oportunidade (Molina Neto, 1995), procurei desenvolver uma reflexão e argumentação teórica sobre problemas identificados no cotidiano da sala de aula, no currículo de formação de professores e na prática docente que os acadêmicos de educação física realizam nas escolas de educação básica e fundamental, sob a forma de estágio supervisionado, prática de ensino ou posto de trabalho.

Orientaram-me no planejamento, na execução, no acompanhamento, e na reflexão sobre este trabalho, princípios como: o compromisso com a escola pública e a crença que os professores produzem conhecimento na sua ação cotidiana de sala de aula, já que como sublinha Morin (1994): conhecimento e ação estão implicados entre si.

Deste modo, a ação e o conhecimento, por sua vez, implicam um no outro, estão unidos entre si e são diferentes um do outro, $(\mathrm{p} .64)^{2}$

Nesse sentido, estabeleceu-se como objetivo examinar a relação entre a produção de conhecimento e a prática docente em educação física através do ensino de uma técnica corporal específica em escolas públicas de Porto Alegre - RS. Em outras palavras, tratou-se de observar a relação entre pesquisa e ensino como elementos intrínsecos à ação docente e dar visibilidade ao conhecimento produzido nesse relacionamento. Assim, o relato da experiência e sua interpretação são apresentados no texto, desde a perspectiva dos acadêmicos de educação física que participaram da mesma.

\section{A DISCIPLINA FUTEBOL:}

\section{TÉCNICAS DE ENSINO}

O atual currículo de formação de professores de Educação Física materializa um processo de disciplinarização científica progressivo - reflexo da patologia do saber contemporâneo, em termos de Sobral (1995) - e de um diálogo de surdos simpáticos (Bracht, 1998) em termos da produção do conhecimento nessa área no Brasil. Esse fato, que tem efeitos significativos na organização do trabalho pedagógico dos professores de educação física nas escolas (Taffarel, 1993; Molina Neto, 1997), recentemente determinou que o currículo fosse revisado e colocado em discussão na área específica de conhecimento e comunidade de especialistas. ${ }^{3}$

O currículo da licenciatura em educação física da ESEF - UFRGS põe em prática o ensino e organiza o saber sobre as diferentes técnicas corporais que o compõem em três níveis de conteúdos disciplinares: Fundamentos, Técnicas Avançadas e Técnicas de Ensino. Dessa forma, o conhecimento sobre o futebol esta distribuído nas seguintes disciplinas: Futebol Fundamentos, Futebol Técnicas Avançadas, Futebol Técnicas de Ensino.

Seguindo orientação da Comissão de Graduação da ESEF - UFRGS, o acadêmico que desejar seguir o viés do rendimento esportivo relacionado ao futebol deverá, dentre outras disciplinas, cursar: Futebol Fundamentos, Futebol Técnicas Avançadas e Metodologia do Treinamento Esportivo. Para os interessados em dedicar-se ao viés do magistério em escolas de educação básica, a Comissão recomenda que o universitário curse as disciplinas de Futebol Fundamentos, Futebol Técnicas de Ensino e Metodologia da Educação Física. Estas disciplinas somadas as demais componentes curriculares capacitariam o professor a programar, executar e avaliar o ensino do futebol nos diferentes âmbitos onde ele acontece, seja no contexto escolar como não escolar.

Para concretizar essas intenções, a disciplina Futebol (poderia ser Voleibol, Atletismo 
ou qualquer outra modalidade esportiva) em seu referente Técnicas de Ensino ${ }^{4}$ oferece aos acadêmicos conhecimentos de didática geral, pedagogia do esporte, programação de ensino, teorias e processos de ensino-aprendizagem e outros relacionados com o desenvolvimento motor da criança e do adolescente. Após um breve período de "nivelamento teórico", os alunos são colocados em situação de sala de aula.

A experiência acumulada como formador de professores e pesquisador (Molina, 1996), tem demonstrado que os procedimentos utilizados nas disciplinas de Técnicas de Ensino não têm produzido os efeitos desejados no preparo dos futuros professores de educação física. Com freqüência, observo que uma parte significativa desses alunos, ao iniciar o estágio supervisionado em escolas de educação básica (obrigatório no currículo de licenciatura), tem revelado, apesar do bom nível de leitura de textos pedagógicos, pouco conhecimento sobre o mundo da escola, falta de competência técnica no âmbito da didática e, inclusive, certo temor para organizar e agir pedagógicamente junto aos alunos da rede pública de ensino.

\section{CONSIDERANDO A DIFERENÇA: POR QUE}

AS TÉCNICAS DE ENSINO NÃO ATENDEM O QUE SE ESPERA DELAS NA FORMAÇÃO

DOS PROFESSORES?

Vários fatores intervém no desenvolvimento de uma disciplina de Técnicas de Ensino como, por exemplo, as expectativas do professor responsável, acadêmicos e grupo de alunos que dela participam. Particularmente, penso que as Técnicas de Ensino não atendem plenamente o que se espera delas. Isto, pelo menos em parte, é decorrência do ambiente onde se realizam, normalmente configurado para grupos-classe cujas condições materiais diferem daquelas encontradas nas escolas públicas, e que são determinantes para o aprendizado do acadêmico e para o conhecimento que ele elabora na sua ação pedagógica. Como sublinha Morin:

Por ser o ato de conhecimento, um ato biológico, cerebral, espiritual, lógico, lingüistico, cul- tural, social, histórico, o conhecimento não pode ser dissociado da vida humana, nem da relação social. (1994:27)

Essa situação se concretiza, em primeiro lugar, porque as crianças e adolescentes que formam o grupo experimental dessas disciplinas têm motivações e interesses diferentes daquelas que participam das aulas de educação física na escola pública. Nas Técnicas de Ensino, as crianças participam movidas por um desejo pessoal, ou induzido, de aprender e praticar uma modalidade esportiva com a qual se identificam. Já na escola pública, mesmo com níveis elevados de participação dos alunos na elaboração do plano de curso, as crianças e adolescentes obedecem a uma normativa institucional e a seleção de conteúdos é feita segundo os interesses e habilidades do professor ou estabelecida pelo currículo escolar.

Quanto ao ambiente, a diferença se evidencia no fato de que as Técnicas de Ensino são desenvolvidas na Escola de Educação Física, espaço físico que o acadêmico domina e sentese socialmente integrado. Ele pode buscar soluções alternativas para problemas apresentados durante a prática, sejam estes intrínsecos ou extrínsecos a sua aula. Por outro lado, as crianças encontram-se num "habitat" diferente do seu, um lugar organizado para recebê-las duas vezes por semana e com normas diferentes das que estão acostumadas. Na escola pública o ambiente predominante é outro, os alunos convivem diariamente uns com os outros o que favorece o estabelecimento de relações interpessoais mais duradouras e onde o ensino da cultura e das técnicas corporais tem um dimensão tecnicamente menos performática e mais socializadora.

No que tange a configuração dos grupos, nas Técnicas de Ensino o critério que prevalece é o interesse pela modalidade esportiva, havendo também uma tendência ao nivelamento quanto às habilidades motoras e faixas etárias. Estes critérios favorecem o alcance de melhores níveis de participação das crianças e dos adolescentes nas aulas, bem como facilita a programação e execução das mesmas pelo professor. Já nos grupos de educação física escolar, o profes-

\section{Nesse sentido, ganha relevância um outro diferencial entre as Técnicas de Ensino e a prática da educação física escolar. Refiro- me ao material didático neces- sário para o ensino e a aprendizagem das técnicas corporais.}


sor encontra desafios à execução de suas aulas não apenas relativas a faixas etárias díspares, como também ao contexto sócio-cultural mais amplo, como por exemplo, gênero, raça e classe social. Estes fatores interferem tanto na participação dos alunos na aula, como influenciam os modos de inserção e intervenção diferenciada do professor de educação física. Cabe aqui lembrar que:

A escola não é uma ilha na sociedade. Não esta totalmente determinada por ela, mas não está totalmente livre dela. Entender os limites existentes para a organização do trabalho pedagógico aju-

Segundo os acadêmicos, esta prática gerou grande aprendizado pela riqueza de informações acessadas sobre o mundo da escola pública e das relações que os alunos mantém nesse ambiente. da-nos a lutar contra eles; desconsiderá-los con$d u z$ a ingenuidade e ao romantismo. (Freitas, 1995:99)

Nesse sentido, ganha relevância um outro diferencial entre as Técnicas de Ensino e a prática da educação física escolar. Refiro-me ao material didático necessário para o ensino e a aprendizagem das técnicas corporais. Enquanto que na primeira, professores e alunos dispõem dos recursos da Escola de Educação Física com qualidade e quantidade suficientes, na educação física escolar eles enfrentam limitações em ambos aspectos. Por via de regra, quanto mais na periferia das grandes cidades estiver localizada a escola pública, menos materiais didáticos terá a disposição para o ensino e a aprendizagem das técnicas corporais.

\section{FORMANDO PROFESSORES PARA A ESCOLA PÚBLICA ATRAVÉS DAS TÉCNICAS DE ENSINO}

Considerando o que foi exposto na seção anterior e convencido de que as técnicas de ensino não possibilitam ao acadêmico de educação física o aprendizado suficiente para o trabalho na escola pública, propus, no primeiro semestre acadêmico de 1997, uma experiência didática aos alunos da disciplina Futebol - Técnicas de Ensino. A experiência consistiu em desenvolver, como parte do programa de educação física em escolas públicas de ensino básico e fundamental, o ensino do futebol em turmas mistas.

Além do ensino da técnica corporal, cada um de nós comprometeu-se a identificar um problema de investigação e sistematizar as reflexões sobre o que aprendemos durante esse período e o conhecimento resultante da experiência. Através da escritura de artigos ou ensaios a serem submetidos ao exame da comunidade docente e do corpo editorial de revistas especializadas, assumimos o compromisso de publicar nossa experiência.

De minha parte, acompanhei o trabalho dos acadêmicos através de observações sistemáticas e procurei ouvir sobre as dificuldades e descobertas ocorridas durante o processo de ensino. Além disso, após as aulas utilizei diálogos argumentativo/construtivos para identificar os sentimentos, impressões e considerações sobre o que haviam feito na mesma. Realizei duas entrevistas coletivas com o grupo e pelo menos uma com cada um dos 11 acadêmicos participantes.

Realizei observações generalizadas e focalizadas das aulas, principalmente, no que tange às relações interpessoais dos participantes com os alunos, das suas formas de intervir junto à turma e no sentido de cumprir o plano de ensino. Os diálogos pós-aula foram registrados no diário de campo e as informações obtidas nas entrevistas foram gravadas e transcritas. Deste material, emergiram as unidades de significado e as principais categorias de análise utilizadas na interpretação da experiência realizada e na escritura desse informe de investigação.

Devo dizer que optei por esses procedimentos metodológicos, tendo em vista a minha concepção da realidade estudada, os meus interesses cognitivos (Habermas, 1982) e o tipo de conhecimento que me interessava produzir, já que segundo Pérez Gomes (1997):

Deste modo, a investigação educativa se propõe superar o vazio entre a teoria e a prática, entre a investigação e a ação, formando e transformando o conhecimento e a ação dos que participam da relação educativa, experimentando ao mesmo tempo que investigando ou reflexionando sobre a prática. Assim pois, o conhecimento que se pretende elaborar neste modelo de investigação se encontra incorporado ao pensamento 
e a ação dos que intervém na prática, o que determina a origem dos problemas, a forma de estudá-los e a maneira de tornar pública a informação, (p. 118)

\section{O RELATO DA EXPERIÊNCIA}

No ato da matrícula, foi distribuído aos acadêmicos interessados em cursar a disciplina de Futebol - Técnicas de Ensino um folheto informando que naquele semestre as atividades seriam desenvolvidas em escolas públicas de ensino básico e fundamental. Como veremos mais adiante, este cuidado não teve total eficácia. Alguns estudantes realizaram a matrícula por procuração não :endo o folheto de instruções chegado as suas mãos, enquanto outros não o receberam do funcionário que efetivou a matrícula. No entanto, aqueles que receberam o material chegaram ao primeiro encontro com grande ansiedade e expectativa quanto ao rrabalho a ser realizado.

Matricularam-se no total 11 acadêmicos, 4 do sexo feminino e 7 masculino, na maioria formandos. Os estudantes foram organizados em 6 duplas, sendo que um dos alunos formou par com o monitor da disciplina. Tendo cursado a disciplina de Futebol - Fundamentos sob a minha direção, este acadêmico já havia experimen tado o ensino do futebol em turmas mistas. Por esta razão, ao invés de constituir um trio, optei que o mesmo trabalhasse com o monitor. As duplas foram lotadas em 5 escolas públicas, 4 de ensino fundamental e 1 de ensino básico, onde cada uma delas assumiu a responsabilidade pelo ensino da educação física de uma turma de $5^{\mathrm{a}}$ à $8^{a}$ série. O trabalho em duplas teve por objetivo possibilitar a observação de eventos e situações do cotidiano da educação física escolar. Além disso, visou oferecer subsídios ao trabalho do cente do acadêmico e servir como coleta de da dos para o trabalho de pesquisa a ser concluído no final do semestre.

A fim de oferecer subsídios para a execução de um trabalho diferenciado daquele que habitualmente acontece nas aulas de educação física do ensino fundamental ( $5^{\mathrm{a}}$ a $8^{\mathrm{a}}$ série), sobretudo no que se refere à grupalização dos alunos tendo como principal critério o sexo, desen- volveu-se nas duas primeiras semanas de aula um trabalho de reflexão e instrumentalização teórica. Os temas eleitos para pautar esse período que antecedeu a chegada deles à escola foram os seguintes:

a) Contextualização da educação física escolar no âmbito de uma pedagogia emancipatória e de uma escola progressista. ${ }^{5}$

b) Instrumentalização teórica no âmbito da pesquisa qualitativa, pesquisa participante, investigação-ação e etnografías educativas. ${ }^{6}$

c) Subsídios para o ensino diferenciado da educação física e dos esportes na escola. ${ }^{7}$

A continuação passamos por um pequeno período de reconhecimento e negociação com os grupos de alunos das escolas e tratamos de elaborar o plano de ensino. Como o conteúdo já estava previamente selecionado (Futebol), os acadêmicos de imediato passaram a efetivação das aulas nas escolas.

No transcurso do trabalho pedagógico os acadêmicos foram orientados a delimitar um problema de investigação. Assim, alternando entre eles os papéis de execução e observação, registravam o ocorrido e/ou percebido para reflexões posteriores. Este fato chamou muito a atenção da turma. Os alunos freqüentemente perguntavam aos acadêmicos o que eles anotavam naqueles "caderninhos". "Seria algum tipo de avaliação?" Para consubstanciar o trabalho de pesquisa, os acadêmicos realizaram entrevistas com os alunos em torno do problema identificado por cada dupla. Segundo os acadêmicos, esta prática gerou grande aprendizado pela riqueza de informações acessadas sobre o mundo da escola pública e das relações que os alunos mantém nesse ambiente. Entre muitas questões interessantes, salientaram-se: as atitudes violentas entre os alunos (verbais e fisicas), a sexualidade e a dificuldade de organização coletiva.

\section{O PENSAMENTO DOS ACADÊMICOS}

A tentativa de produção de conhecimen-

\section{$A$ atividade de ensino do futebol em turmas mistas também desen- cadeou proble- mas. Alguns relacionados a especificidade do ensino dessa modalidade, $e$ outros ao âmbito mais amplo das relações profes- sor-aluno em sala de aula.}




\section{As acadêmicas do sexo feminino tiveram que redobrar esforços para organizar $e$ executar as atividades de aula tendo em vista que tiveram que superar a auto- desqualificação culturalmente incorporada quanto ao saber sobre futebol. $\mathrm{Na}$ sociedade brasileira, este tipo de conheci- mento está vinculado e é comumente considerado de "propriedade" do gênero masculino.}

to e a atividade de pesquisa a partir das práticas de ensino dos professores nas escolas, se não chega a ser propriamente uma novidade no que se refere a formação de professores, também não é uma constante. Segundo Elliot (1993), o movimento dos professores como investigadores emerge na Inglaterra dos anos sessenta durante as reformas curriculares da grammar school. No Brasil, os estudos de Piconez (1991) e Fazenda (1991) mostram como os alunos de Pedagogia podem compreender a realidade escolar e desenvolver um processo de análise sistemática de sua prática docente através da atividade investigadora e reflexiva na sala de aula.

No âmbito da educação física, particularmente no que se refere ao ensino das técnicas corporais, esses projetos não têm a freqüência desejada. Por um lado, estes estudos não despertam o interesse da comunidade de especialistas, tendo em vista que a escola deixou de ter o protagonismo no mercado de trabalho desse coletivo docente. Por outro lado, essas questões não alcançam o "status" necessário para chamar a atenção dos investigadores de reconhecido saber. Uma exceção recente parece ser o estudo de Terra (1997). Nele a autora se propõe estimular o estudante de educação física a investigar e sistematizar o conhecimento obtido no ensino de handebol no âmbito da licenciatura. De todas as formas, vale o registro de que as pesquisas sobre a prática docente estão mais orientada pelas exigências dos programas de pós-graduação do que pela necessidade de resolver os problemas substantivos que os professores enfrentam no cotidiano da escola.

Esse mesmo objetivo foi um dos guias da experiência aqui relatada. Nesse sentido, apresento na seqüência desse estudo as representações (Minayo, 1995) dos alunos em torno a seu aprendizado durante o transcurso da mesma.

Em primeiro lugar a experiência representou, na visão dos acadêmicos, uma forma diferente de organizar o trabalho pedagógico, desviante da maioria das disciplinas que haviam vivenciado no curso. Nesse sentido, para eles, a própria estrutura curricular se constitui num entrave para a sua realização e de outras expe- riências inovadoras, uma vez que o horário de realização da disciplina, a ordem e o processo de efetivação de matrícula são ações já "naturalizadas" pela forma tradicional de organização do trabalho pedagógico nas disciplinas. A disciplina esta localizada entre outras no horário do curso. Isto dificulta o deslocamento do acadêmico para a escola. Por outro lado, a obtenção de vagas na disciplina está condicionada à ordem de matrícula. Isto faz com que os possíveis interessados não tenham a oportunidade de uma prática de ensino diferenciada antes de chegar ao estágio supervisionado. O contrário também é verdadeiro. Pela necessidade de somar créditos, pode ocorrer que algum acadêmico sem o devido interesse pela atividade veja-se "obrigado" a cursar a disciplina.

Ainda do ponto de vista estrutural, as escolas públicas onde foram realizadas a experiência ofereceram grandes dificuldades tais como: a) organização das turmas em faixas etárias bastante amplas; b) carência de material didático apropriado; c) espaço físico pouco organizado e inseguro para realização de atividades físicas. Por outro lado, estes fatores desafiaram os acadêmicos a desenvolver estratégias didáticas criativas para alcançar seus objetivos de ensino, como também os levaram ao aprendizado do manejo e da necessidade de mediar seus interesses com grupos heterogêneos e conflitivos. Para a maioria dos acadêmicos, além deste aprendizado, a experiência serviu para que pudessem diferenciar e compreender a importância de bem dimensionar os objetivos da iniciação esportiva em espaços não escolares, evidenciados em seu aprendizado na maioria das disciplinas do currículo a que foram submetidos, dos do ensino da educação fisica escolar.

A atividade de ensino do futebol em turmas mistas também desencadeou problemas. Alguns relacionados a especificidade do ensino dessa modalidade, e outros ao âmbito mais amplo das relações professor-aluno em sala de aula. $\mathrm{Na}$ perspectiva dos acadêmicos, observou-se uma resistência inicial dos meninos para aprender e jogar futebol junto com as meninas. Segundo eles, a aceitação por parte dos meninos das $8^{\text {as }}$ séries foi mais tranqüila do que pelos 
meninos de $6^{a s}$ series. A explicação encontrada para este fato foi de que nas $\sigma^{\text {as }}$ séries os meninos têm nas atividades físicas o centro de sua ação cotidiana e, estando ainda no início da adolescência, encontram-se em vias de construção e afirmação de sua masculinidade. É através do vigor físico e da agressividade que tentam se diferenciar das meninas, procurando assumir no relacionamento entre ambos o papel dominante sugerido pela cultura na qual estão inseridos. Nesse sentido, durante as atividades com as $6^{\text {as }}$ séries ocorreram agressões físicas tanto entre os meninos, quanto entre meninos e meninas.

De outra parte, nas $8^{a s}$ séries, estando os meninos mais avançados no processo de socialização promovido pela escola e com a sexualidade mais apurada, desejam a presença das meninas, trabalhando com elas sem maiores dificuldades. Em relação as meninas, não foi possível detectar contraste no nivel de participação entre as turmas, pois tanto nas $6^{a s}$ séries como nas séries mais avançadas, elas revelaram grande disponibilidade para trabalhar essa modalidade esportiva junto com os meninos, mesmo que com comentários jocosos dos meninos quan-To a feminilidade daquelas que revelavam destreza e habilidade no jogo de futebol. Os acadêmicos pontuaram que possivelmente a boa participação das meninas tenha relação com a publicidade que a mídia vem fazendo em torno dos jogadores de futebol e a prática desse esporte pelas mulheres.

As acadêmicas do sexo feminino tiveram que redobrar esforços para organizar e executar as atividades de aula tendo em vista que tiveram que superar a auto-desqualificação culturalmente incorporada quanto ao saber sobre futebol. Na sociedade brasileira, este tipo de conhecimento está vinculado e é comumente considerado de "propriedade" do gênero masculino. Pela mesma razão, tiveram que enfretar o descrédito por parte dos alunos do sexo masculino. Esta situação fica mais evidenciada nas $5^{a s}$ e $6^{a s}$ séries. Nesta faixa escolar, os procedimentos didáticos ia educação física estão fortemente centrados no binômio demonstração-execução e os alunos e alunas, tecnicamente, apresentam maiores dificuldade para executar os fundamentos da mo- dalidade esportiva em questão. Nesse sentido, o depoimento de Sara é ilustrativo:

O que mais aprendi...foi eu acho assim... que não é nem a questão da técnica, porque logo fiquei bem preocupada quando tinha que ensinar futebol, porque se dou um chute para um lado a bola vai lá do outro lado...então a primeira coisa que fiquei preocupada era isso. Como é que vou ensinar futebol? A teoria era tranqüilo. Fui lá montava as aulas perfeitíssimas, mas com a prática, na hora de estar na prática que era o difícil. Então eu acho que me superei, porque tinha horas que até quando nós começamos a dividir os grupos..., para o meu colega era mais fácil, a prática em si, né. E eu tinha que me virar. Eu tinha que me superar, para que um guri ficasse prestando a atenção numa mulher ensinando como é que se chuta, ensinando como é que é...então era dificil, né. Então eu acho que todo esse momento que tive dentro da aula, dentro da prática em si, quero dizer assim, os maiores momentos que aconteciam, situações de aula e que eu e o José tínhamos que resolver, eu acho que esse foi o maior aprendizado, com certeza.

A realização da investigação em conjunto com a ação docente, bem como a sistematização dos resultados obtidos em ambas atividades na forma de um trabalho acadêmico, foi de grande dificuldade para os estudantes devido a pouca utilização deste tipo de investigação no âmbito da educação física. Soma-se a isto o fato deste modelo ser pouco socializado aos futuros professores da área. Conforme Cláudio:

Sobre o trabalho, eu acho que é bem importante de continuar. Por exemplo, aqui mesmo na universidade, se tu prestares bem a atenção...agora ...tá...agora construíram a estrutura nova do Centro de Excelência, o novo LAPEX ... a maioria das pesquisas da instituição fica voltada para a parte mais técnica. O impacto disso, o pé no chão, a diminuição do percentual corporal, quando o corpo é imerso dentro d'água, isso e aquilo e são poucos os trabalhos que estão voltados mais para o lado social. Na realidade esse estudo não deixa de ser nada mais do que da área social. Para ver como é a integração dos diferentes sexos dentro de uma atividade, usando um esporte que ... historicamente..."

Os acadêmicos demonstraram pouca dificuldade na apropriação e utilização de procedimentos e técnicas de investigação qualitativa como, por exemplo, efetuar observações seletivas do cotidiano da escola e da aula, registrar essas observações, e relatar impressões em diá-

\section{Com freqüência, a compreensão da realidade onde estavam imersos, a interpretação dos fenômenos e a construção teórica dos significados eram confundi- das com a comprovação, avaliação e comparação com outros contextos.}


rio durante o trabalho de campo. Em contrapartida, revelaram grande dificuldade na identificação e delimitação de um problema, na interpretação das informações e, principalmente, na compreensão dos processos lógicos envolvidos no tipo de trabalho que realizavam. Com freqüência, a compreensão da realidade onde estavam imersos, a interpretação dos fenômenos e a construção teórica dos significados eram confundidas com a comprovação, avaliação e comparação com outros contextos. Essa situação é curiosa uma vez que tratando-se de alunos-formandos os mesmos haviam cursado a disciplina de Metodologia da Pesquisa e, portanto, deveriam conhecer esse tipo de processo metodológico.

Um dos trabalhos de conclusão da disciplina foi ampliado e resultou em uma comunicação científica apresentada no X Salão de Iniciação Científica da UFRGS. Uma dupla de acadêmicos não entregou o trabalho e dois foram concluídos depois das observações que realizei. Estes dada a qualidade apresentam condições para serem publicados. Outros dois trabahos foram encaminhados aos autores sendo considerados como tarefa escolar concluída.

Após a finalização da experiência, ficou evidenciada a diferença de expectativas professor-aluno, isto é, entre o que eu e eles esperávamos da disciplina antes de cursá-la. De um lado, estava eu, o professor-pesquisador, entusiasmado com a atividade investigadora. De outro lado, estavam os alunos preocupados com questões de outra natureza, igualmente relevantes e legítimas: concluir os créditos da licenciatura nas condições de tempo e organização pessoal. Meu objetivo era transferir aos alunos esse entusiasmo e os conhecimentos necessários para que realizassem com efetividade uma pesquisa em sala de aula. Era também meu interesse experimentar com os acadêmicos o modelo de pesquisa que considero relevante para responder importantes questões educacionais ainda à espera de uma compreensão mais satisfatória. Os acadêmicos objetivavam na disciplina uma aprendizagem habilitadora ao exercício profissional do magistério.
É importante destacar que nesta experiência tivemos que negociar nossos interesses. Desta forma, ainda que as produções acadêmicas não tenham correspondido plenamente ao ideal desejado, isso não invalida o experimentado, nem desqualifica seus objetivos. Formar professores-investigadores de sua própria prática não é tarefa de apenas uma disciplina. Estou convencido de que uma tarefa de tal envergadura requer profundas e necessárias transformações no âmbito da cultura docente dos professores de educação física e de paciência pedagógica, em termos da pedagogia Freireana. De qualquer forma, sublinho que do começo ao fim da experiência que realizamos os acadêmicos tiveram a oportunidade de exercitar com consciência a intencionalidade política na sua ação pedagógica e isto me parece um ganho significativo.

\section{CONSIDERAÇÕES FINAIS - TÉCNICAS DE ENSINO: PREPARAÇÃO PARA \\ O ESTÁGIO E PARA PROFISSÃO DOCENTE}

Penso que as disciplinas de Técnicas de Ensino conforme o proposto nessa experiência didática, além de permitir o exercício da docência da modalidade esportiva pelos futuros professores, pode ajudá-los na aproximação e imersão no ambiente da escola pública. Dessa forma, imprime bases mais sólidas para que o Estágio Curricular Supervisionado em escolas, ao final do curso, seja uma atividade menos traumática e mais articulada com o currículo da licenciatura em Educação Física. Assim, compreendendo a especificidade do ambiente escolar, talvez seja possível reverter, pelo menos em parte, o desinteresse que os acadêmicos vêm demonstrando para trabalhar como professores em escolas públicas.

Por outro lado, tenho evidências para acreditar que o conhecimento pedagógico e a aprendizagem adquirida neste processo superou os manuais prescritivos de prática de ensino disponíveis nas bibliotecas especializadas. Na medida em que tiveram que negociar soluções contextualizadas para atender as diferentes necessidades apresentadas pelos alunos durante as au- 
las de educação física, os acadêmicos abandonaram a visão idealizada de aluno e da profissão docente, fato que ampliou seu saber profissio-nal. Em termos de Pérez Gomes (1994):

"O conhecimento dos docentes deve formar-se em um complexo e prolongado processo de conhecimento na ação (saber-fazer) e de reflexão em e sobre a ação (saber pensar e investigar). Assim o conhecimento relevante para orientar a pratica do docente na vida cambiante e incerta da aula, quando se propõe facilitar o desenvolvimento da compreensão em seus alunos, surge e aparece na reflexão sobre as características e processos de sua própria prática, em todas as dimensões de sua ampla acepção: planejamento, desenvolvimento e avaliação. Entretanto, como afirma Elliot (1985), o professor que desenvolve suas teorias a partir unicamente da reflexão sobre a experiência, deixando de lado as reflexões passadas e presentes dos demais, acaba inventando a roda. (p.17)

Evidenciou-se, na ação docente dos estudantes e na dificuldade dos mesmos em investirá-la de acordo com o modelo proposto, o quanto o currículo de formação de professores está desarticulado e distante das necessidades da escola. Isto não chega a ser uma novidade. No entanto, no que tange a realização da pesquisa durarte a ação docente, a dificuldade apresentada pelos acadêmicos não encontra-se no desconhe-cimento das técnicas de coleta de dados e da atividade hermenêutica. O cerne dessa dificuldade está na incongruência da lógica de pesquisar e conhecer no âmbito da educação física enquanto área de conhecimento e na lógica de pesquisar e conhecer necessária para o âmbito e ques-tões fundamentais da prática docente da educação física escolar. Esta incongruência imprime neste coletivo pouca credibilidade neste modelo de investigação.

Explicitar isso, parece-me apropriado para revitalizar o debate sobre a formação dos professores de educação física, já que segundo Elli-ott (1993) a institucionalização da investigação-ação e dos professores como investigadores enquanto enfoque fundamental da formação de professores nas instituições universitárias suscita uma série de questões críticas sobre as quais todos devemos refletir. Se queremos facilitar uma prática reflexiva como forma de investigação educativa nas escolas na busca de solução de seus problemas, também devemos fomentar a formação dos professores como prática reflexiva através de uma atividade investigadora compatível.

\section{REFERÊNCIAS BIBLIOGRÁFICAS}

BRACHT, Valter (1998). Um pouco de história para fazer história: 20 anos do CBCE. Revista Brasileira de Ciências do Esporte. $\mathrm{N}^{\circ}$. especial, set/ 98.

ELLIOTT, John (1993). El cambio educativo desde la investigación-acción. Madrid. Morata. [Edição original em inglês, Action Research For Education Change. Open University Press, 1991.]

FAZENDA, Ivani Catarina Arantes (1991). O papel do estágio nos cursos de formação de professores. In: PICONEZ, Stela C. Bertholo (Coord.), A Prática de Ensino e o Estágio Supervisionado, pp. 53-62. Campinas: Papirus.

FREITAS, Luis Carlos de (1995). Critica da organização do trabalho pedagógico. Campinas, Papirus.

HABERMAS, Jürgen (1982). Conocimiento $e$ interes. Madrid. Taunus. [Edición original en alemán, Erkenntnis und Interese, Frankfurt: Suhrkanp Verlag, 1968.]

MINAYO, Maria Cecília de Souza (1995). O conceito de representações sociais dentro da sociologia clássica. In: GUARESCHI, P. Jovchelovitchi (Orgs.) Textos em representações sociais. Petrópolis: Vozes.

MOLINA NETO, Vicente (1995). Uma experiencia de ensino do futebol no currículo da licenciatura em Educação Física. Movimento. Ano 2, vol. 2,jun/95.

MOLINA NETO, Vicente (1996). La cultura docente del professorado de educación física de las escuelas públicas de Porto Alegre. Tesis Doctoral. Universidad de Barcelona, Departamento de Didáctica y Organización Educativa.

MOLINA NETO, Vicente (1997). A formação profissional em educação física e esportes. Revista Brasileira de Ciências do Esporte, vol. 19. n 1, 1997/2, pp. 34-41.

MORIN, Edgar (1994). El método III: El conocimiento del conocimiento. Madrid: Cátedra. [Edição original em francês: La Méthode III: La connaissance de la connaissance, Seuil, 1986.]

PÉREZ GOMES, Ángel I. (1997). Comprender la 
enseñanza en la escuela. Modelos metodológicos de investigação educativa. In: GIMENO SACRISTÁN, José, \& PÉREZ GOMES, Ángel

I. (Orgs.) Comprender y Transformar la Enseñanza ( $7^{\text {a }}$ reimp.). pp. $115-136$ Madrid: Morata.

PÉREZ GOMES, Ángel I. (1994). Comprender y enseñar a comprender. In: ELLIOTT, John. La investigación-acción en la educación. Madrid: Morata.

PICONEZ, Stela C. Bertholo (1991). A Prática de ensino e o estágio supervisionado: a aproximação da realidade escolar e a prática da reflexão. In: PICONEZ, Stela C. Bertholo, A Prática de Ensino e o Estágio Supervisionado, pp. 15-38. Campinas: Papirus.

SOBRAL, Francisco (1995). Cientismo e credulidade ou patologia do saber em ciências do desporto. Revista Movimento. Ano II, n 3, pp. $07-$ 16.

TAFFAREL, Celi Nelza Zulke (1993). A formação do profissional da educação: O processo de trabalho pedagógico e o trato com o conhecimento no curso de educação física. Tese de Doutorado. Universidade Estadual de Campinas, Faculdade de Educação,

TERRA, Dinah Vasconcellos (1991). Ensino crítico-participativo das disciplinas técnico desportivas nos cursos de licenciatura em educação física. In: MENEZES, Vera Lúcia (org.), Formação Profissional Universitária em Educação Física, pp. 201- 233. Rio de Janeiro: Universidade Gama Filho.

\section{NOTAS}

${ }^{1}$ Escola de Educação Física da Universidade Federal do Rio Grande do Sul.

2 A tradução dos textos dos autores estrangeiros aqui citados é de minha responsabilidade.

${ }^{3}$ Refiro-me ao trabalho iniciado e desencadeado pela
Comissão de Especialistas em Educação Física convocada pelo MEC. Vale registrar que essa revisão esta fortemente associada e acentuada pela edição da LDB (Lei n 9.394/96), os PCNs e pela regulamentação da profissão de professor de Educação Física (Lei n ${ }^{\circ} .6$ 96/98).

${ }^{4}$ Visando atender as determinações da Lei ${ }^{\circ} 9.394 /$ 96, art.65, que prevê 300 horas de prática de ensino para a formação docente, a Comissão de Graduação da ESEF - UFRGS, criou uma sub-área de estágio supervisionado denominada técnicas de ensino, num total de 150 horas, a ser acrescentada às 150 horas de estágio curricular em escolas de educação básica, historicamente presente nos cursos de formação de professores de educação física. Essa sub-área engloba todas as disciplinas cujo objetivo é oportunizar ao acadêmico o exercício do ensino das diferentes técnicas corporais no âmbito da educação escolar e não escolar. Na continuidade do texto utilizarei Técnicas de Ensino, como indicativo genérico para referir-me ao conjunto, e a cada uma das disciplinas, cujo objetivo é ensinar a ensinar determinada técnica corporal ou modalidade esportiva.

${ }^{5}$ Da obra de Paulo Freire, foram utilizadas os livros: Pedagogia do Oprimido, Pedagogia da Esperança e Pedagogia da Autonomia e da obra de Henry Giroux o livro Os professores Como Intelectuais.

${ }^{6}$ Utilizei o livro Pesquisa Participante de Carlos Rodrigues Brandão e partes do livro La investigaciónaccion en educación de Jonh Elliott.

${ }^{7}$ Foram importantes para esta reflexão o trabalho do Coletivo de Autores e a obra de Elenor Kunz, princi palmente o título: Transformação Didático Pedagógica do Esporte.

\section{UNITERMOS}

Educação Física; formação de professores; escola pública.

* Vicente Molina Neto é professor Doutor Titular da Escola de Educação Física da Universidade Federal do Rio Grande do Sul. 